\title{
Kinetic Study of Dehydration of Calcium Oxalate Trihydrate
}

\author{
P. Honcová ${ }^{1 *}$, R. Svoboda ${ }^{1}$, P. Pilný ${ }^{1}$, G. Sádovská ${ }^{1}$, J. Barták $^{1}$, L. Beneš ${ }^{1}$, D. Honc ${ }^{2}$
}

${ }^{1}$ Faculty of Chemical Technology, University of Pardubice, Studentská 573, 53210 Pardubice, Czech Republic

${ }^{2}$ Faculty of Electrical Engineering and Informatics, University of Pardubice, Cs. Legii Sq. 565, 53002 Pardubice, Czech Republic

Copyright (C) 2016 Springer

DOI $10.1007 / \mathrm{s} 10973-015-5110-2$

\begin{abstract}
The dehydration of calcium oxalate trihydrate was studied using DSC method and open sample crucibles. The dehydration proceeds in two steps where first two molecules of water are released around $80{ }^{\circ} \mathrm{C}$ and consequently the last molecule of water is released at a temperature around $130{ }^{\circ} \mathrm{C}$. The kinetic analysis of overlapping peaks was done and the apparent activation energy, pre-exponential factor and kinetic exponents of kinetic model (reaction order model) were evaluated for both effects.
\end{abstract}

Keywords: Calcium oxalate trihydrate; Dehydration; Kinetics; DSC; Reaction order; Deconvolution

\section{Introduction}

The calcium oxalate $\mathrm{CaC}_{2} \mathrm{O}_{4}$ forms three hydrates, stable and naturally occurring monohydrate (COM) and two metastable, dihydrate (COD) and trihydrate (COT) $[1,2]$. Each form of hydrate can be easily recognised because COM usually precipitates in the form of dendrites or boat/coffin morphology, COD shows a bipyramidal morphology and COT gives plate-like morphology $[3,4]$. Calcium oxalates were up to now frequently studied as chemicals involved in formation of urinary calculi [5,6], main attention is paid to finding the factors and conditions giving support to calcium oxalate and consequently to kidney stone formation $[7,8]$. The most frequently published data on calcium oxalate describe the crystal growth (conditions and kinetics) [3,9-18] and dissolution of hydrates [19-22]. The crystallization of $\mathrm{COM}$ has been the subject of physico-chemical and biological analyses [23,24]. Recently a

\footnotetext{
*pavla.honcova@upce.cz; tel. No.+420466037179
} 
nephron fluid dynamics model has been proposed [25] that integrates crystallization kinetics, crystal size distribution and allows predicting of the nucleation and growth rates of COM.

Thermal decomposition studies of oxalates are not so frequently published except for data on COM [26-28]. The dehydration of stable COM was studied many times by thermoanalytical methods (thermogravimetry, TG; differential scanning calorimetry, DSC; differential thermal analysis, DTA) and this process was often used to test several methods of kinetic analysis [29-31]. Metastable COT is not mentioned so often, but the work of Skrtic et al. [32] describes kinetics of spontaneous precipitation of COT and Gardner [33] published data for nucleation and crystal growth of COT. Nishikawa et al. [34] synthesized single crystal of COT from dimethyl oxalate in the aqueous solution of calcium chloride $(\mathrm{pH}=3$ and $3^{\circ} \mathrm{C}$ ) and studied it by thermal analysis and single crystal X-ray structure analysis. The activation energies for the two step dehydration reactions were calculated to be $87.9 \mathrm{~kJ} \mathrm{~mol}^{-1}$ (for $-2 \mathrm{H}_{2} \mathrm{O}$ dehydration) and $105.3 \mathrm{~kJ} \mathrm{~mol}^{-1}$ (for $-\mathrm{H}_{2} \mathrm{O}$ dehydration) and the corresponding change of enthalpy was 573 and $289 \mathrm{~J} \mathrm{~g}^{-1}$, respectively. The dehydration of COT to the thermodynamically stable monohydrate form has also been studied in aqueous solutions at various supersaturations in the temperature range of $25-40^{\circ} \mathrm{C}$ [35]. It has been found that the solid state nucleation and growth of COM takes place after the macroscopic growth and agglomeration of the trihydrate crystals occurs. The concluding processes probably involve solution growth and ageing of the newly formed monohydrate crystals and the overall dehydration process has an approximate activation energy of $188 \mathrm{~kJ} \mathrm{~mol}^{-1}$ [35].

This paper focuses on the DSC study of dehydration of COT and kinetic analysis of obtained effects. The authors' main effort is to complete the kinetic information about calcium oxalate hydrates.

\section{Kinetic analysis}

The measured heat flow $\Phi$ can be described by the kinetic equation [36]

$$
\Phi=\Delta H A \exp \left(\frac{-E}{R T}\right) f(\alpha)
$$

where $\Delta H$ is the enthalpy of the process, $A$ is the pre-exponential factor, $E$ is the apparent activation energy, $R$ is a gas constant and $T$ is temperature. The function $f(\alpha)$ is an analytical expression of the kinetic model where $\alpha$ is a degree of conversion.

Equation (1) can be rewritten in a logarithmic form [37,38]:

$$
\ln \Phi_{\alpha, i}=\ln [\Delta H \cdot A \cdot f(\alpha)]-E_{\alpha} / R T_{i}
$$


where the subscript $\alpha$ denotes values related to a given extent of fractional conversion. The basic assumption in kinetic analysis of solid state processes is that the expression of the kinetic model, $f(\alpha)$ does not depend on temperature or heating rate. Therefore, the first term in the right hand side of Eq.(2) should be constant and the activation energy $E_{\alpha}$ can be evaluated from the slope of the plot $\ln \Phi_{\alpha, \mathrm{i}}$ vs. $1 / T_{\mathrm{i}}$ obtained from several experiments carried out at different temperatures or heating rates. The linearity of this plot is an important test of the validity of Eq.(1). This isoconversional method can be applied for both, isothermal and nonisothermal data and it enables the determination of the activation energy as a function of $\alpha$. The other frequently used methods of $E$ determination applicable only to non-isothermal experiments base on the shift of the temperature corresponding to the maximum of observed peak $T_{p}$ with the heating rate $\beta$. The assumption of these methods is that the degree of conversion is constant at temperature of $T_{p}$ for all conditions used. Kissinger [39] proposed method where the slope of the $\ln \left(\beta / T_{p}{ }^{2}\right)$ dependence on $1 / T_{p}$ is equal to the $-E / R$. Similar method was published by Ozawa [40] where the slope of the $\ln (\beta)$ dependence on $1 / T_{p}$ is equal to $-1.052 E / R$.

When the activation energy of observed process is calculated then the following step of kinetic analysis is determination of suitable kinetic model. Very simple way how to test the applicability of commonly used model is calculation of function $y(\alpha)$ and $z(\alpha)$ [41]. Under non-isothermal conditions the functions are defined as [38]:

$$
\begin{aligned}
& y(\alpha)=\Phi \exp \left(-\frac{E}{R T}\right) \\
& z(\alpha)=\Phi T^{2}
\end{aligned}
$$

These functions are normalized within the $\langle 0,1\rangle$ range and they exhibit maxima at $\alpha_{M}$ and $\alpha_{p}^{\infty}$, respectively. The exact values of these maxima or their relation as well as the shape of the curves $y(\alpha)$ and $z(\alpha)$ suggest a suitable kinetic model as is described in papers [38,42]. As the $\mathrm{y}(\alpha)$ and $\mathrm{z}(\alpha)$ functions are invariable with respect to temperature or heating rate, being quite sensitive to subtle changes in the kinetic model $f(\alpha)$, they can be conveniently employed as suitable tools for the kinetic model determination [38].

Another way of suitable kinetic model testing is determination of symmetry of observed DSC peak. Málek and Criado [43,44] described procedure of peak shape analysis using inflectional asymmetry parameters and correlated this asymmetry with kinetic model parameters. The value of appropriate shape index, $S$, and the inflection temperature ratio $T_{1} / T_{2}$ ( $T_{1}$ and $T_{2}$ are temperatures corresponding to the first and second inflection points on DSC 
curve, respectively) leads to selection of appropriate kinetic model describing experimental data.

In this work, first the applicability of commonly used models for description of dehydration of calcium oxalate trihydrate is tested and then the parameters are calculated.

\section{Experimental}

The calcium oxalate trihydrate was prepared by mixing solution of calcium chloride and oxalic acid according the equation:

$$
\mathrm{CaCl}_{2}+\mathrm{H}_{2} \mathrm{C}_{2} \mathrm{O}_{4}+3 \mathrm{H}_{2} \mathrm{O} \rightarrow \mathrm{CaC}_{2} \mathrm{O}_{4} \cdot 3 \mathrm{H}_{2} \mathrm{O}+2 \mathrm{HCl}
$$

The condition of precipitation (mainly temperature, $\mathrm{pH}$ and ionic strength) influences the numbers of formed hydrates. The amount of $1.5 \mathrm{dm}^{-3}$ of calcium chloride solution with concentration $0.02 \mathrm{~mol} \mathrm{dm}^{-3}$ and $\mathrm{pH} 1.3$ (pH modified by $\mathrm{HCl}$ ) was kept at temperature $12{ }^{\circ} \mathrm{C}$. Then the solution was mixed with propeller stirrer and $45 \mathrm{ml}$ of oxalic acid solution with concentration $0.5 \mathrm{~mol} \mathrm{dm}^{-3}$ was added from dropper during 10 minutes. The mixture was continuously mixed another 30 minutes and the temperature was kept at $12{ }^{\circ} \mathrm{C}$. Then the solution was filtered $(0.22 \mu \mathrm{m}$ filter $)$ and the solid phase was washed by cold distilled water, ethanol and finally with ether. The calcium oxalate trihydrate (COT) is formed under these conditions as was confirmed by X-ray diffraction. The prepared COT was stored at the temperature $-6^{\circ} \mathrm{C}$ before the calorimetric experiments and other analyses were done.

The dehydration of calcium oxalate trihydrate was studied in solid state by using heatflow differential scanning calorimeter (DSC Q2000, TA Instruments) equipped with an autosampler, RSC90 cooling accessory, and T-zero technology. The instrument was calibrated using $\mathrm{In}, \mathrm{Zn}$ and $\mathrm{H}_{2} \mathrm{O}$; dry $\mathrm{N}_{2}$ was used as purge gas at a flow rate of $50 \mathrm{~cm}^{3} \mathrm{~min}^{-1}$. Fresh zero-line calibration was performed before the measurements. The sample (amount approx. 2 mg) was put into the standard aluminium pan without any cover (to eliminate water evaporated from the sample and its influence on observed process); the empty pan was used as a reference. The calcium oxalate trihydrate was measured in the temperature range from 0 to $220{ }^{\circ} \mathrm{C}$ and the heating rates of $0.5,1,2,3,5,7,10,15$ and $20 \mathrm{~K} \mathrm{~min}^{-1}$ were applied. The amount of dehydrated water was measured by thermogravimetry using a TG/DTA Jupiter STA 449 instrument where the heating rate $10 \mathrm{~K} \mathrm{~min}^{-1}$ was applied in the temperature range from 30 to $300^{\circ} \mathrm{C}$.

The dehydration process was also observed by Olympus BX51 microscope with DP 72 camera (micrographs were taken in transmission mode) during heating using Linkam THMS600 heating stage from room temperature to $250{ }^{\circ} \mathrm{C}$. The plate-like or prism shape of 
COT crystals is illustrated in Fig 1. The original shape and size of these crystals at room temperature (Fig 1A) is similar to those obtained for crystals heated up to $220^{\circ} \mathrm{C}$ (Fig 1B). However, the originally transparent crystals became dark during dehydration.

The composition of product obtained after partial and final dehydration was checked by X-ray diffraction using a Bruker AXS X-ray diffractometer equipped with horizontal goniometer and scintillation counter, utilizing Ni-Filtered $\mathrm{CuK}_{\alpha}$ radiation $(40 \mathrm{kV}, 30 \mathrm{~mA})$. The scans were taken over scattering angles, $2 \theta$ from $10^{\circ}$ to $45^{\circ}$ at a scanning speed of $0.4^{\circ}$ $\min ^{-1}$. The prepared COT was firstly analysed at room temperature, then the temperature was changed to $101^{\circ} \mathrm{C}$ and kept for the time (45 min) necessary to complete the diffractogram and finally the temperature was changed to $210{ }^{\circ} \mathrm{C}$ and again kept to obtain diffractogram at this temperature.

\section{Results and discussion}

The dehydration of the calcium oxalate trihydrate proceeds in two steps observed as two endothermic peaks on DSC curve (Fig. 2). Generally, two molecules of water are lost in temperature range of $20-110{ }^{\circ} \mathrm{C}$, and the last molecule of water is lost in temperature range of 70-170 ${ }^{\circ} \mathrm{C}$ depending on the heating rate used for the measurement. The amount of dehydrated water in each step was confirmed by thermogravimetry.
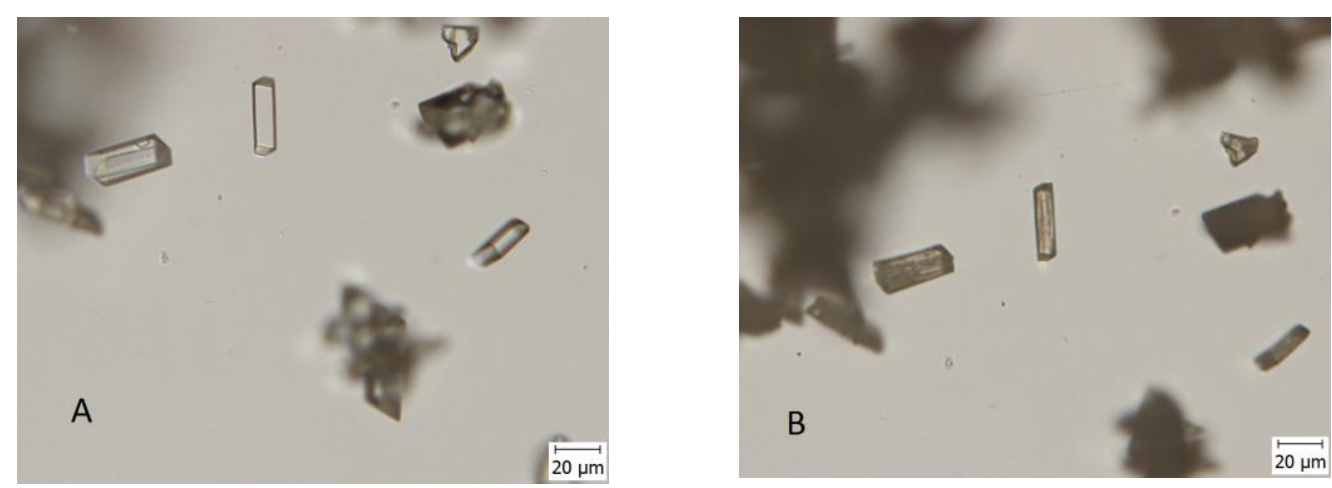

Fig. 1: Illustration of COT crystals at room temperature (A) and heated to $220^{\circ} \mathrm{C}(\mathrm{B})$.

The dehydration effects occur at the temperature around $100{ }^{\circ} \mathrm{C}$ where some moisture from the sample can evaporate too. The verification of this presumption was done when the COT sample was kept 2 days in the silica gel desiccator at the temperature of $-6{ }^{\circ} \mathrm{C}$ (in following text this sample is referred to as predried) and consequently measured by TG. The selected conditions of drying should be sufficient to eliminate excessive moisture from COT as is described in Ref. [34]. The theoretical mass change for the first dehydration of 2 molecules of water is $19.8 \%$ and for the second dehydration of the last molecule of water is 
$9.9 \%$ with regard to original mass of COT. The thermogravimetric results were the same for predried sample and sample without any treatment. The mass change obtained by TG was $19.0 \%$ for the first effect and $10.2 \%$ for the second effect which is close to the theory and confirmed that any evaporation of the moisture did not significantly influence the dehydration of water proceeding around the temperature of $100{ }^{\circ} \mathrm{C}$.

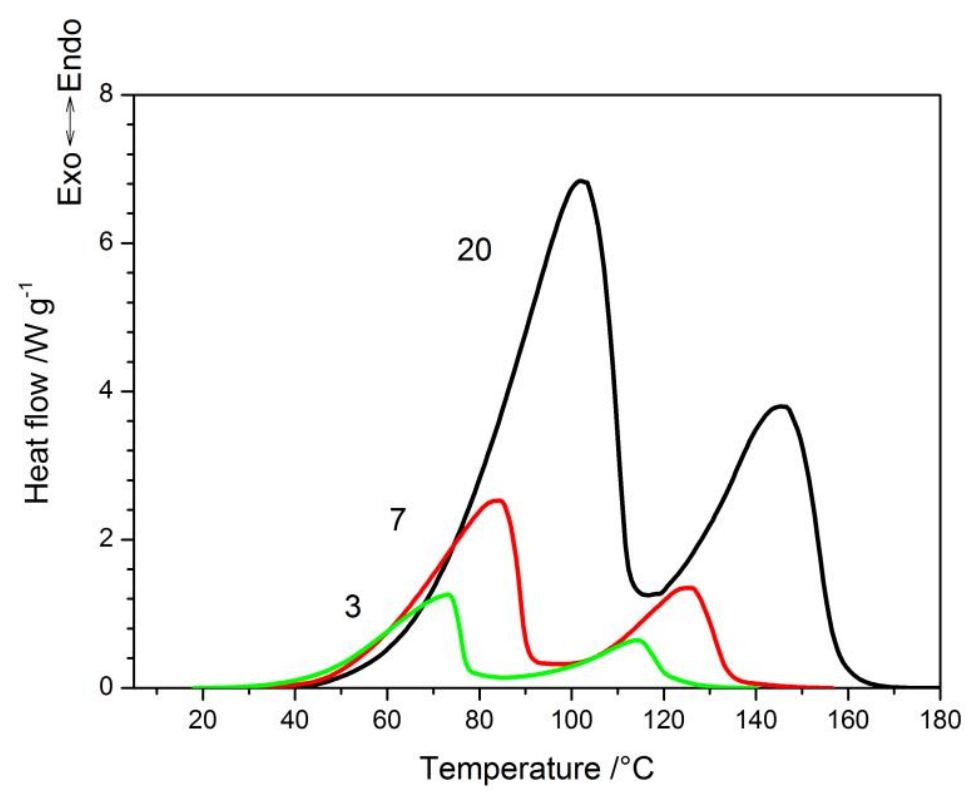

Fig. 2: DSC scan of COT performed at heating rates 3, 7 and $20 \mathrm{~K} \mathrm{~min}^{-1}$.

Table I: Parameters describing COT dehydration measured using different heating rates: $\Delta H$ enthalpy change of both the effects, $T_{\mathrm{p}}$ temperature corresponding to the maxima of the first and second dehydration peaks

\begin{tabular}{cccc}
\hline $\begin{array}{c}\text { Heating rate } \\
/ \mathrm{K} \mathrm{min}^{-1}\end{array}$ & $\Delta H / \mathrm{J} \mathrm{g}^{-1}$ & $\begin{array}{c}T_{\mathrm{p}} /{ }^{\circ} \mathrm{C} \\
1^{\mathrm{st}} \text { effect }\end{array}$ & $\begin{array}{c}T_{\mathrm{p}} /{ }^{\circ} \mathrm{C} \\
2^{\text {nd }} \text { effect }\end{array}$ \\
\hline 0.5 & 904.8 & 51.0 & 91.9 \\
1 & 865.6 & 58.6 & 99.8 \\
2 & 839.5 & 67.6 & 108.8 \\
3 & 821.9 & 73.0 & 114.2 \\
5 & 820.6 & 80.5 & 121.9 \\
7 & 808.0 & 84.3 & 125.6 \\
10 & 855.3 & 88.8 & 130.3 \\
15 & 860.8 & 95.3 & 138.2 \\
20 & 926.7 & 102.0 & 145.8 \\
average & $850 \pm 35$ & & \\
\hline
\end{tabular}


X-ray powder diffraction showed that prepared calcium oxalate trihydrate has triclinic structure with lattice parameters $a=6.1017 \AA, b=7.1480 \AA, c=8.4488 \AA, \alpha=76.53^{\circ}, \beta=$ $70.27^{\circ}$ and $\gamma=70.68^{\circ}$. When this sample is heated above the first dehydration effect (temperature of $101{ }^{\circ} \mathrm{C}$ for about 45 minutes of $\mathrm{X}$-ray measurement is enough to dehydrate first amount of water but to keep the last water amount) the monoclinic structure of calcium oxalate monohydrate was confirmed with lattice parameters $a=6.2906 \AA, b=14.5912 \AA, c=$ $10.1375 \AA$. and $\beta=109.12^{\circ}$. The product of total dehydration was analysed when the sample was heated to $210^{\circ} \mathrm{C}$ and the X-ray diffraction showed that it contained anhydrous calcium oxalate with monoclinic structure and lattice parameters $a=9.8363 \AA, b=14.7459 \AA, c=$ $6.3070 \AA$ and $\beta=106.40^{\circ}$. The obtained diffractograms are illustrated in Fig. 3.

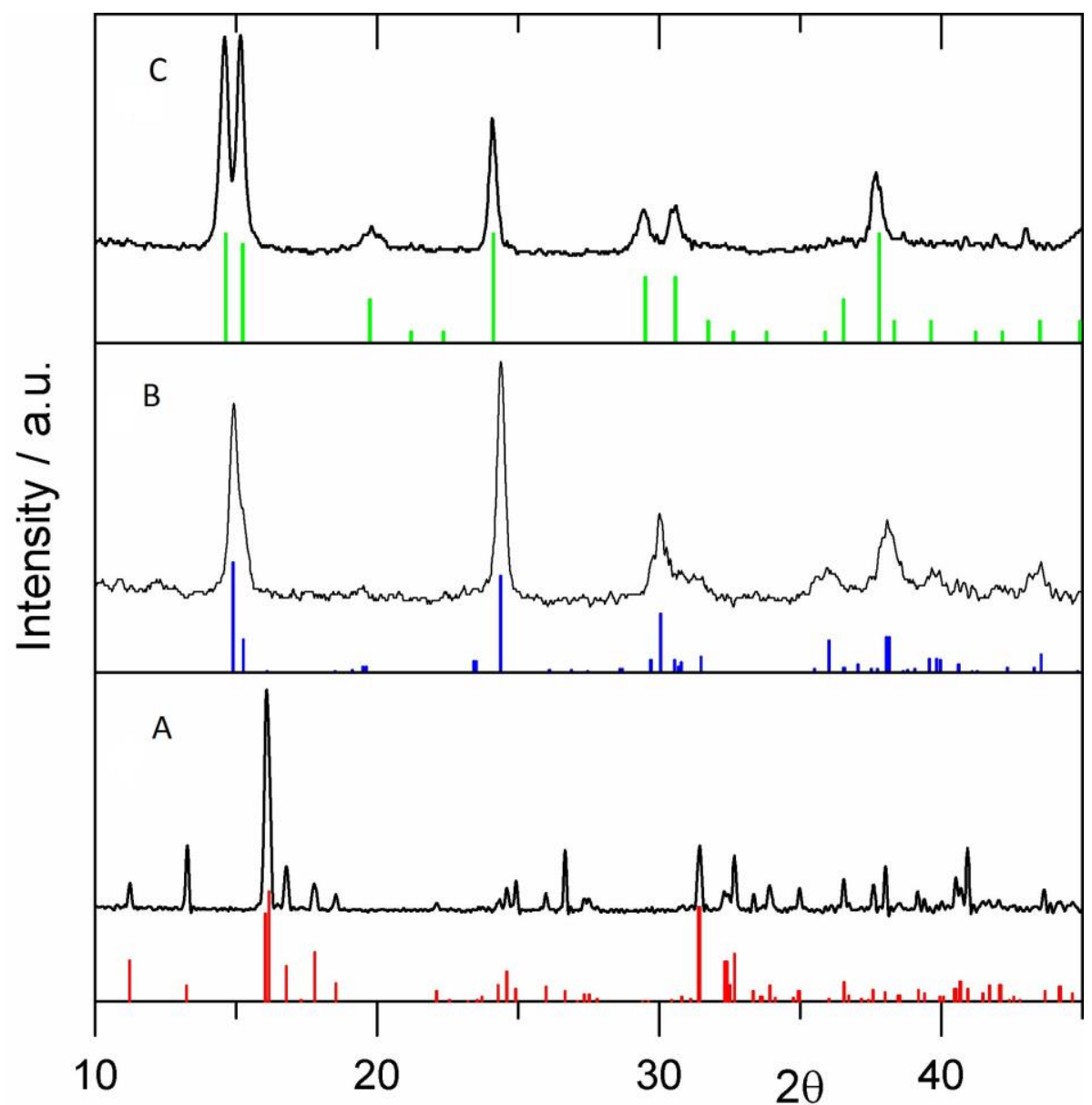

Fig. 3: XRD diffractograms of prepared COT sample at: A) room temperature, B) $101{ }^{\circ} \mathrm{C}, \mathrm{C}$ ) $210{ }^{\circ} \mathrm{C}$ compared with standards from PDF-4+ database shown as bar diagrams: red for $\mathrm{CaC}_{2} \mathrm{O}_{4} \cdot 3 \mathrm{H}_{2} \mathrm{O}$ (JCPDS No 04-014-9825), blue for $\mathrm{CaC}_{2} \mathrm{O}_{4} \cdot \mathrm{H}_{2} \mathrm{O}(04-011-6806)$ and green for $\mathrm{CaC}_{2} \mathrm{O}_{4}(00-021-0838)$. 


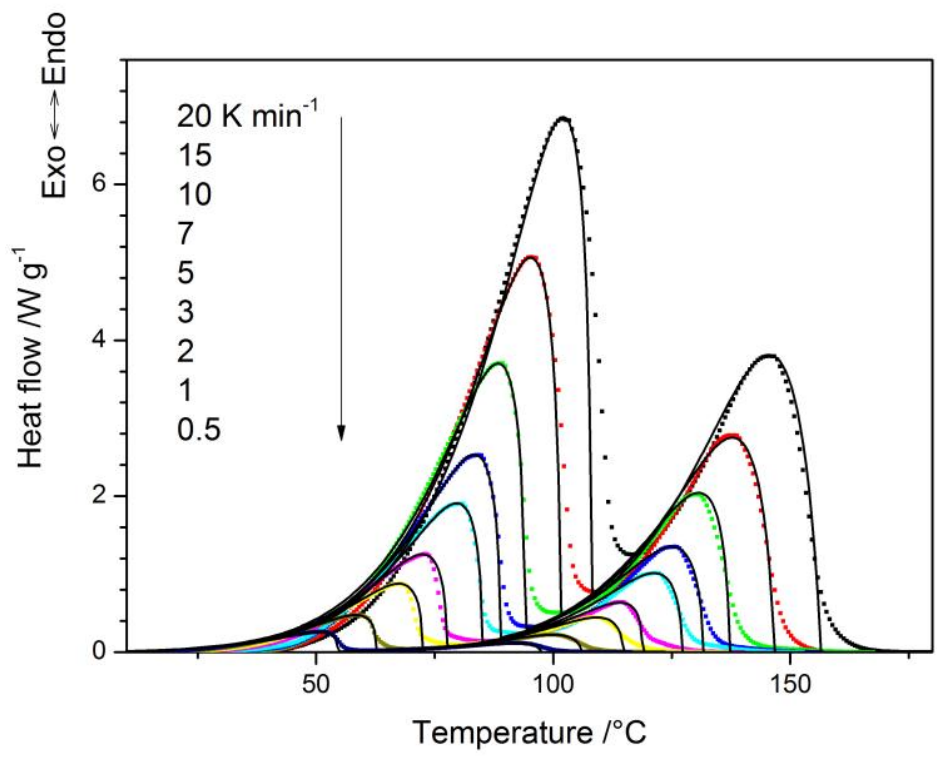

Fig. 4: The non-isothermal data of dehydration of COT for different heating rates. The theoretical dependences (lines) are calculated for parameters summarized in Table II.

As can be seen in Fig. 2 both dehydration peaks are joined together. In the case of overlapping DSC peaks the application of low heating rate can help to separate observed processes but in the case of COT dehydration not even the low rate as $0.5 \mathrm{~K} \mathrm{~min}^{-1}$ leads to separation of overlapping peaks (see Fig. 4). The area under the DSC peak (calculated as a total area below overlapping peaks) is used to determine the enthalpy of the process directly from experimental data and its value for each heating rate is given in Table I. The average value of $\Delta H$ for both the effects of $850 \pm 35 \mathrm{~J} \mathrm{~g}^{-1}$ is comparable with $862 \mathrm{~J} \mathrm{~g}^{-1}$ published by Nishikawa [34].

The kinetic analysis of both the dehydration effects was done using the set of DSC data obtained for heating rates from 0.5 to $20 \mathrm{~K} \mathrm{~min}^{-1}$ as is shown in Fig. 4. The first and the most important step in kinetic analysis of DSC data is determination of the apparent activation energy. The second step of kinetic analysis consists in selection of the appropriate kinetic model and its parameters. In the case of overlapping peaks only evaluation of activation energy based on $T_{\mathrm{p}}$ shift with the heating rate can be done. Figure 5 shows heating rate dependence on $T_{\mathrm{p}}$ in the form necessary for Kissinger method [39] as was described above in Kinetic analysis part. The linear fit of these dependences gives values of $E$ equal to $68.6 \pm 1.2$ $\mathrm{kJ} \mathrm{mol}^{-1}$ and $82.7 \pm 2.3 \mathrm{~kJ} \mathrm{~mol}^{-1}$ for the first and second effect, respectively. Similar values of apparent activation energy were obtained when the Ozawa method [40] was applied, i.e. 74.4 $\pm 1.2 \mathrm{~kJ} \mathrm{~mol}^{-1}$ for the first effect and $89.2 \pm 2.3 \mathrm{~kJ} \mathrm{~mol}^{-1}$ for the second effect. Both values of 
$E$ are a bit lower compared to results published by Nishikawa et al. [34] (as is described in introduction it is $87.9 \mathrm{~kJ} \mathrm{~mol}^{-1}$ for the first peak and $105.3 \mathrm{~kJ} \mathrm{~mol}^{-1}$ for the second peak) but our experiments were done in much broader range of heating rates than the published experiments. The second effect, i.e. dehydration of one water molecule can be compared with results for calcium oxalate monohydrate. The DSC measurement of COM under isothermal conditions [29] gives the value of $E$ equal to $82.8 \mathrm{~kJ} \mathrm{~mol}^{-1}$ and the thermogravimetry curves [30] gives $E$ between 97 and $125 \mathrm{~kJ} \mathrm{~mol}^{-1}$. Both these values are close to our results for the second effect.

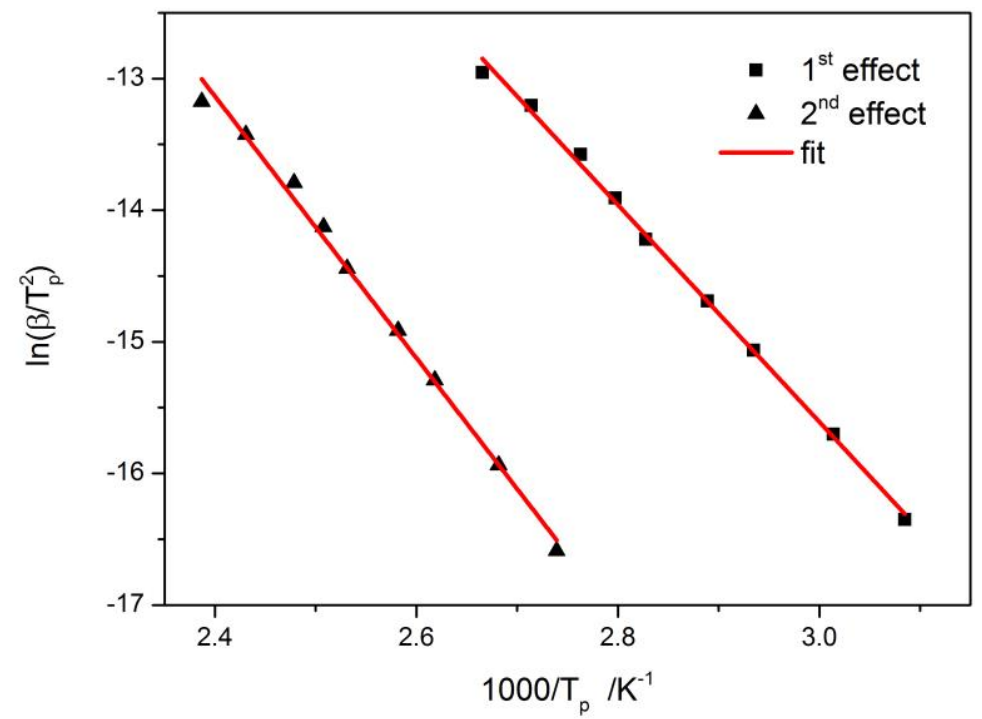

Fig. 5: The Kissinger method dependence of temperature corresponding to the maximum $T_{\mathrm{p}}$ on heating rate $\beta$ of the first and second dehydration peak (points). Lines correspond to linear fit of data.

The full kinetic analysis (i.e. determination of $E$, selection of appropriate kinetic model and determination of parameters of this model) can be applied when the deconvolution of observed overlapping peaks is performed. The best for deconvolution process is simple numerical fitting using general equation describing various shapes of DSC peaks such as Fraser-Suzuki [45-47] function or deconvolution based on selected function (published in $[48,49])$.

The Fraser-Suzuki function was tested (program Peakfit, Systat Software Inc.). The Fraser-Suzuki function is expressed as [45]: 


$$
y=a_{0} \exp \left[-\ln 2\left[\frac{\ln \left(1+2 a_{3} \frac{x-a_{1}}{a_{2}}\right)}{a_{3}}\right]^{2}\right]
$$

where $a_{0}, a_{1}, a_{2}$ and $a_{3}$ are the parameters corresponding to the amplitude, position, half-width and asymmetry of the curve, respectively. As is described by Perejón et al. [46] Fraser-Suzuki function is able to fit the shape of all kinetic curves obtained under linear heating conditions, independently of their kinetic parameters. Surprisingly, this function was not able to fully follow the shape of the first effect of our results. Thus, the deconvolution of the curves was done to follow the decreasing part of the first effect - the part which is involved in convolution of effects. The illustration of deconvoluted peaks and their comparison with experimental data is given in Fig. 6.

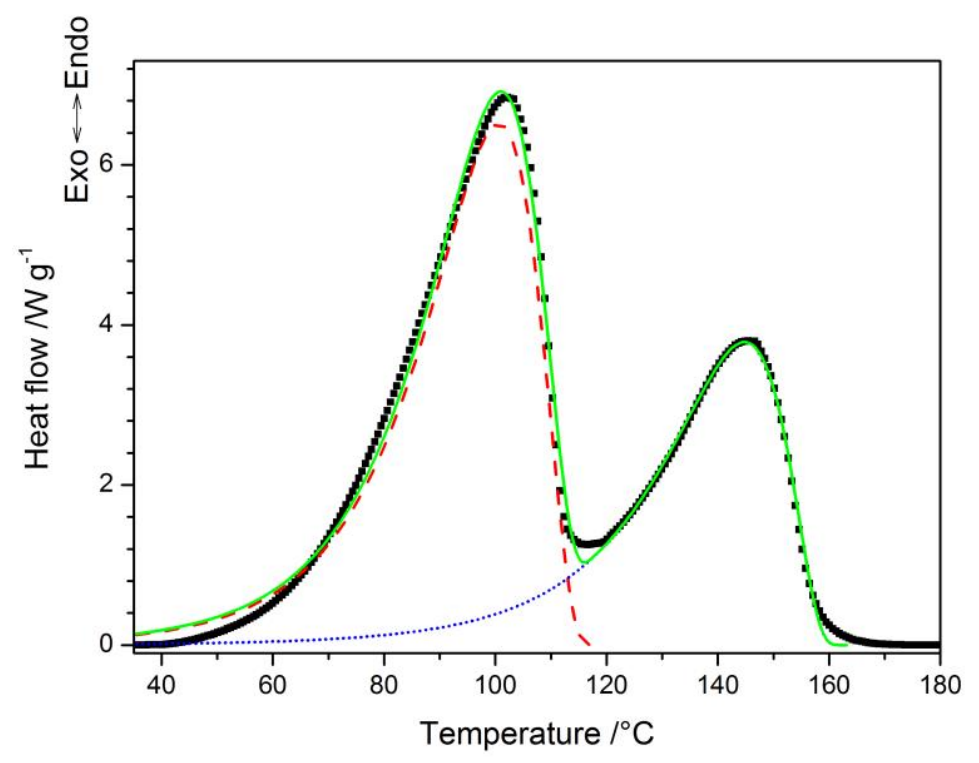

Fig. 6: Comparison of experimental data (points) with deconvoluted curves (dash and dot line) and their summary (solid line) for DSC scan done by rate of $20 \mathrm{~K} \mathrm{~min}^{-1}$.

These two sets of deconvoluted data were used to performed classical kinetic analysis for single peak. The kinetic analysis of DSC data (overlapping as well as deconvoluted) was done using software OriTas [50] where the standard kinetic equations are used for calculations and the appropriate model describing experimental data is selected on the base of characteristic functions introduced by Málek [41,42]. In the case of our DSC curves different modules of OriTas software were used to estimate values of parameters describing both effects and to 
select the kinetic model. Then these preliminary parameters and models were specified in the module for deconvolution to obtain the best simulation of experimental data.
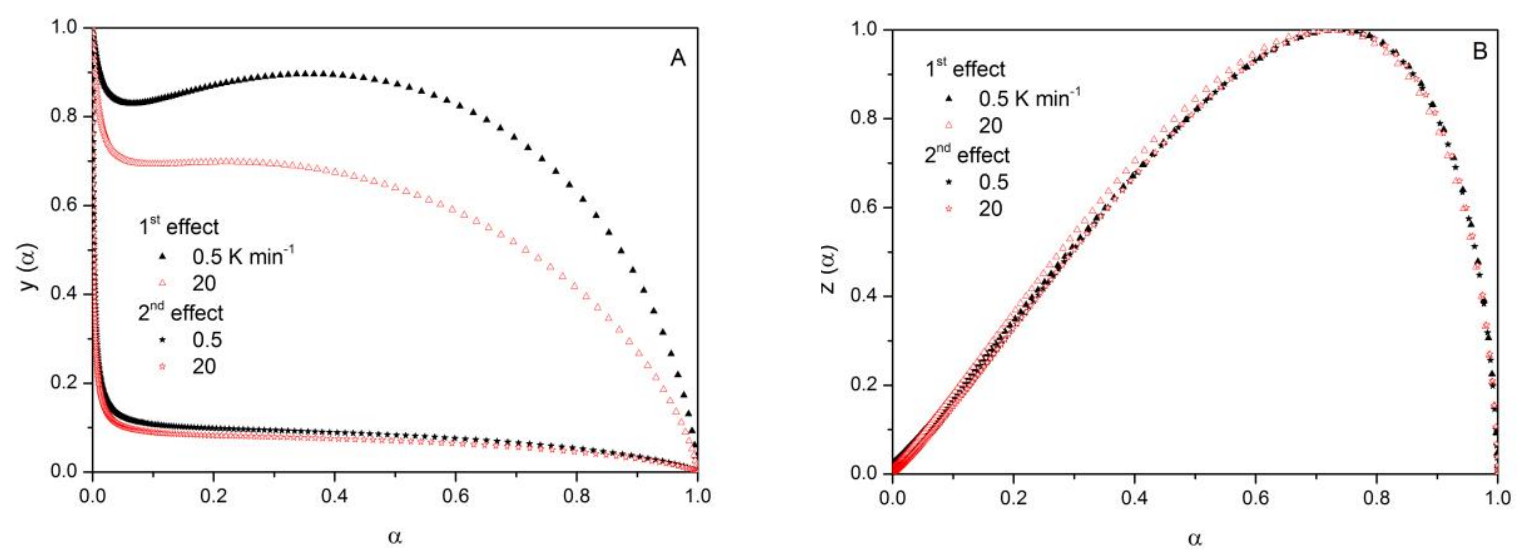

Fig. 7: Normalized $y(\alpha)$ and $z(\alpha)$ functions obtained by transformation of non-isothermal data for COT dehydration of 2 molecules of water ( $1^{\text {st }}$ effect) and last molecule of water $\left(2^{\text {nd }}\right.$ effect) for different heating rates -0.5 and $20 \mathrm{~K} \mathrm{~min}^{-1}$.

The analysis of each set of deconvoluted peaks showed that in both cases the selection of kinetic description can be similar. The experimental data were transformed into the function $y(\alpha)$ and $z(\alpha)$ according to Eqs. (3) and (4) and the illustration of characteristic function dependence on conversion is given in Fig. 7. The conversion corresponding to the maximum of function $z(\alpha)$ is 0.74 for the first effect and 0.75 for the second effect, respectively. As is clearly seen, the conversion corresponding to the maximum of $y(\alpha)$ function is 0 for both effects. Concerning the shape and conversion corresponding to the maximum of both characteristic functions the reaction order (RO) model with parameter $\mathrm{n}<1$ is the appropriate one. Selection of reaction order using characteristic functions is consistent with results when the symmetry of the peak is evaluated. In the case of both sets of deconvoluted peaks the lack of the second inflection point of the DSC curve can be observed which indicates that the process can be described using reaction order with parameter $\mathrm{n} \leq 0.5$ [41].

The parameter $\mathrm{n}(\mathrm{n} \neq 0)$ of $\mathrm{RO}$ model can be calculated iteratively using the equation

$$
\alpha_{p}=1-\left[1+\frac{1-n}{n} x_{p} \pi\left(x_{p}\right)\right]^{1 /(n-1)}
$$

where $\alpha_{\mathrm{p}}$ is conversion corresponding to the maximum of the peak, $x_{\mathrm{p}}$ is reduced activation energy at the peak maximum $\left(x_{\mathrm{p}}=E / R T_{\mathrm{p}}\right)$ and $\pi\left(x_{\mathrm{p}}\right)$ is the expression of temperature integral. 
This equation was derived originally by Gorbachev [51] for $\pi\left(x_{\mathrm{p}}\right)=1 /\left(x_{\mathrm{p}}+2\right)$. Applying this method to both sets of deconvoluted data the value of parameter $n$ equal to $0.52 \pm 0.03$ was obtained for the first effect and $0.49 \pm 0.03$ for the second effect, respectively.

Table II: Kinetic parameters obtained by deconvolution process describing the first and the second effect of COT dehydration for different heating rates: $\Delta H$ enthalpy change of each effect, $A$ pre-exponential factor and parameter $n$ of reaction order model.

\begin{tabular}{ccccccc}
\hline $\begin{array}{c}\text { Heating rate } \\
/ \mathrm{K} \mathrm{min}^{-1}\end{array}$ & $\Delta H / \mathrm{J} \mathrm{g}^{-1}$ & $\begin{array}{c}1^{\text {st }} \text { effect } \\
\ln \left(A / \mathrm{s}^{-1}\right)\end{array}$ & $n$ & $\Delta H / \mathrm{J} \mathrm{g}^{-1}$ & $\begin{array}{c}2^{\text {nd }} \text { effect } \\
\ln \left(A / \mathrm{s}^{-1}\right)\end{array}$ & $n$ \\
\hline 0.5 & 595 & 17.36 & 0.26 & 300 & 19.86 & 0.32 \\
1 & 581 & 17.44 & 0.28 & 308 & 19.94 & 0.35 \\
2 & 573 & 17.44 & 0.30 & 310 & 19.94 & 0.31 \\
3 & 560 & 17.48 & 0.30 & 290 & 20.00 & 0.27 \\
5 & 528 & 17.48 & 0.30 & 300 & 20.00 & 0.31 \\
7 & 508 & 17.56 & 0.30 & 300 & 20.08 & 0.34 \\
10 & 533 & 17.58 & 0.30 & 320 & 20.06 & 0.32 \\
15 & 510 & 17.54 & 0.32 & 320 & 20.00 & 0.40 \\
20 & 523 & 17.40 & 0.30 & 363 & 19.80 & 0.46 \\
average & $546 \pm 30$ & $17.48 \pm 0.07$ & $0.30 \pm 0.02$ & $312 \pm 20$ & $19.96 \pm 0.09$ & $0.34 \pm 0.05$ \\
\hline
\end{tabular}

Taking these preliminary results into consideration the fitting procedure of overlapping peaks was done and the best results of simulation were obtained when the kinetics of the first and second effect was described by reaction order model with parameter equal to 0.30 and 0.35 , respectively. The values of parameter of RO model, pre-exponential factor and enthalpy change for each heating rate are summarized in Table II. The value of apparent activation energy used for simulation process was $66.4 \mathrm{~kJ} \mathrm{~mol}^{-1}$ for the first and 82.6 $\mathrm{kJ} \mathrm{mol}^{-1}$ for the second effect. The second effect, i.e. dehydration of one water molecule can be compared with results for calcium oxalate monohydrate, where published $\Delta H$ value is 495.8 $\mathrm{J} \mathrm{g}^{-1}$ [52] and recalculated for the weight of COT it is $398 \mathrm{~J} \mathrm{~g}^{-1}$ which is higher as compared to our results.

The theoretical dependences of the heat flow on temperature calculated using the parameters summarised in Table II for each heating rate are compared with the experimental data in Fig. 4. As is seen a relatively good agreement between theoretical and experimental data was obtained. Again, we can try to compare the second effect with the results obtained 
for dehydration of COM, where Liqing and Donghua [29] described the isothermal DSC data by reaction order model with parameter $n=1.4-2.4$ which is significantly higher than our results.

\section{Conclusion}

The DSC method was used to study the dehydration of calcium oxalate trihydrate using open crucibles to eliminate any vapour pressure influence on observed process. The dehydration proceeds in two overlapping steps where first two molecules of water are lost around the temperature of $80{ }^{\circ} \mathrm{C}$ and then the last molecule of water is released at temperature around $130{ }^{\circ} \mathrm{C}$. As was confirmed by thermogravimetry, any moisture caused by preparation, storage or handling of the samples did not significantly influence the dehydration effect obtained around the temperature of $100{ }^{\circ} \mathrm{C}$. The product of partial dehydration, dehydration of two water molecules, was identified as calcium oxalate monohydrate and fully dehydrated sample composed of anhydrous calcium oxalate. The kinetic analysis of both the dehydration effects was done using deconvolution procedure and for both effects the reaction order model was determined as the most suitable one.

\section{Acknowledgement}

Authors thank to prof. Petra Šulcová for her help with TG measurements. This work has been supported by IGA University of Pardubice under the research project SGSFChT_2015005.

\section{References}

1. Grases F, Millan A, Conte A. Production of calcium-oxalate monohydrate, dehydrate or trihydrate - a comparative study. Urol Res. 1990;18:17-20.

2. Brečevic Lj, Škrtic D, Garside J. Transformation of calcium-oxalate hydrates. J Cryst Growth 1986;74:399-408.

3. East CP, Wallace AD, Al-Hamzah A, Doherty WOS, Fellows CM. Effect of poly(acrylic acid) molecular mass and end-group functionality on calcium oxalate crystal morphology and growth. J App Polym Sci. 2010;115:2127-35.

4. Donnet M, Jongen N, Lemaitre J, Bowen P. New morphology of calcium oxalate trihydrate precipitated in a segmented flow tubular reactor. J Mater Sci Lett. 2000;19:749-50. 
5. Kohutová A, Honcová P, Podzemná V, Bezdička P, Večerníková E, Louda M, Seidel J. Thermal analysis of kidney stones and their characterization. J Therm Anal Calorim. 2010;101:695-99.

6. Kaloustian J, Pauli AM, Pieroni G, Portugal H. The use of thermal analysis in determination of some urinary calculi of calcium oxalate. $\mathrm{J}$ Therm Anal Calorim. 2002;70:959-73.

7. Walton RC, Kavanagh JP, Heywood BR, Rao PN. Calcium oxalates grown in human urine under different batch conditions. J Cryst Growth 2005;284:517-29.

8. Buchholtz NP, Kim DS, Grover PK, Ryall RL. Calcium oxalate crystallization in urine of healthy men and women: a comparative study. Scanning Microscopy 1996;10:435-44.

9. Söhnel O, Kroupa M, Franková G, Velich V. Calcium oxalate crystallization kinetics from calorimetric measurements. Thermochim Acta 1997;306:7-12.

10. Jung T, Kim W-S, Choi CK. Biomineralization of calcium oxalate for controlling crystal structure and morphology. Materials Sci Engin. 2004;C24:31-3.

11. Rodgers AL, Garside J. The nucleation and growth-kinetics of calcium-oxalate in the presence of some synthetic urine constituents. Investigative Urology 1981;18:484-8.

12. Kavanagh JP, Jones L, Rao PN. Calcium oxalate crystallization kinetics at different concentrations of human and artificial urine, with a constant calcium to oxalate ratio. Urol Res. 1999;27:231-7.

13. Yue WJ, Nie GJ, Chen ZX, Li YB, Xu QQ. Influence of different kinds of polysacharides on crystal growth of calcium oxalate in microemulsion, Assian $\mathrm{J}$ Chem. 2011;23:319-22.

14. Fischer V, Landfester K, Muñoz-Espí R. Stabilization of calcium oxalate metastable phases by oligo(L-glutamic acid): effect of peptide chain length. Crystal Growth\&Design 2011;11:1880-90.

15. Akyol E, Öner M. Controlling of morphology and polymorph of calcium oxalate crystals by using polyelectrolytes. J Cryst Growth 2014;401:260-5.

16. Castello MF, Grupioni CV, Nunes RS, Luiz JM. Thermal behavior of $\mathrm{Ca}^{2+}$ and $\mathrm{Cu}^{2+}$ oxalates obtained by precipitation in homogeneous solution from dimethyl oxalate hydrolysis. J Therm Anal Calorim. 2014;117:1145-50.

17. Farmanesh S, Chung J, Sosa RD, Kwak JH, Karande P, Rimer JD. Natural promoters of calcium oxalate monohydrate crystallization. J Am Chem Soc. 2014;136:12648-57.

18. King HE, Matter DC, Plümper O, Geisler T, Putnis A. Forming cohesive calcium oxalate layers on marble surfaces for stone conservation. Cryst Growth Des. 2014;14:3910-7. 
19. Gutzow I, Atanassova S, Budevsky G. Kinetics of dissolution of calcium-oxalate calculi in physiological solutions containing hippuric-acid. Cryst Res Technol. 1991;26:53354.

20. Hodgkinson A. Solubility of calcium oxalate in human urine, simulated urine, and water. Investigative Urology 1980;18:123-6.

21. Tomažič B, Nancollas GH. Kinetics of dissolution of calcium-oxalate hydrates. J Cryst Growth 1979;46:355-61.

22. Streit J, Tran-Ho L, Königsberger E. Solubility of the three calcium oxalate hydtares in sodium chloride solutions and urine-like liquors. Monats Chemie 1998;129:1225-36.

23. Kevrekidis PG, Whitaker N. Effect of backleak in nephron dynamics. Phys Rev. E 2003;67:061911.

24. Sheng X, Ward MD, Wesson JA. Crystal surface adhesion explains the pathological of calcium oxalate hydrates in kidney stone formation. J Am Soc Nephrol. 2005;16:1904-8.

25. Borissova A, Goltz GE, Kavanagh JP, Wilkins TA. Reverse engineering the kidney: modelling calcium oxalate monohydrate crystallization in the nephron. Med Biol Eng Comput. 2010;48:649-59.

26. Patnaik U, Muralidhar J. Thermal decomposition of rare-earth-doped calcium oxalate: 1. Doping with lanthanum, samarium and gadolinium. Thermochim Acta 1996;274:261-72.

27. Anderson HL, Kemmler A, Höhne GWH, Heldt K, Strey R. Round robin test on the kinetic evaluation of a complex solid state reaction from 13 European laboratories. Part 1. Kinetic TG-analysis. Thermochim Acta 1999;332:33-53.

28. Frost RL, Weier ML. Thermal treatment of whewellite - a thermal analysis and Raman spectroscopic study. Thermochim Acta 2004;409:79-85.

29. Liqing L, Donghua C. Application of iso-temperature method of multipl rate to kinetic analysis. J Therm Anal Calorim. 2004;78:283-93.

30. Budrugeac P, Segal E. Nonisothermal kinetics of reactions whose activation-energy depends on the degree of conversion. Thermochim Acta 1995;260:75-85.

31. Mianowski A. The Kissinger law and isokinetic effect - Part I. Most common solutions of thermokinetic equations. J Therm Anal Calorim. 2003;74:953-73.

32. Skrtic D, Markovic M, Komunjer Lj, Furedi-Milhofer H. Precipitation of calcium oxalates from high ionic-strength solutions. 1. Kinetics of spontaneous precipitation of calcium-oxalate trihydrate. J Cryst Growth 1984;66:431-40.

33. Gardner GL. Nucleation and crystal-growth of calcium-oxalate trihydrate. J Cryst Growth 1975;30:158-68. 
34. Nishikawa Y, Takahashi K, Masunari Y, Okabe M, Yoshidam M, Ohota M. Synthesis of calcium-oxalate trihydrate crystal by homogeneous precipitation method and its structuralanalysis. J Chem Soc Japan 1994;7:661-6.

35. Gardner GL. Kinetics of dehydration of calcium-oxalate trihydrate crystals in aqueoussolution. J Colloid Interface Sci. 1976;54:298-310.

36. Šesták J. Thermophysical properties of solids, their measurements and theoretical analysis. Amsterdam: Elsevier; 1984.

37. Friedman HL. Kinetics of thermal degradation of char-forming plastics from thermogravimetry. Application to phenolic plastic. J Polym Sci. 1964;C6:183-95.

38. Málek J, Mitsuhashi T, Criado JM. Kinetic analysis of solid-state processes. J Mater Res. 2001;16:1862-71.

39. Kissinger HE. Reaction kinetics in differential thermal analysis. Anal Chem. 1957;29:1702-6.

40. Ozawa T. Kinetic analysis of derivative curves in thermal analysis. J Therm Anal. 1970;2:301-24.

41. Málek J. Kinetic analysis of crystallization processes in amorphous materials. Thermochim Acta 355 2000;355:239-53.

42. Málek J. The kinetic analysis of nonisothermal data. Thermochim Acta 1992;200:25769.

43. Málek J, Criado JM. The shape of thermoanalytical curve and its kinetic information content. Thermochim Acta 1990;164:199-209.

44. Málek J. The shape of thermoanalytical curves as a function of the reaction kinetics. Thermochim Acta 1993;222:105-13.

45. Fraser RDB, Suzuki E. Resolution of overlapping bands. Functions for simulating band shapes. Anal Chem. 1969;41:37-9.

46. Perejón A, Sánchéz-Jiménez PE, Criado JM, Pérez-Maqueda LA. Kinetic analysis of complex solid-state reactions. A new deconvolution procedure. J Phys Chem. B 2011;115;1780-91.

47. Svoboda R, Málek J. Applicability of Fraser-Suzuki function in kinetic analysis of complex crystallization processes. J Therm Anal Cal. 2013;111;1045-56.

48. Moharram AH, Abu El-Oyoun M, Rashad M. Crystallization kinetics of two overlapped phases in $\mathrm{As}_{40} \mathrm{Te}_{50} \mathrm{In}_{10}$ glass. Thermochim Acta 2013;555;57-63. 
49. Liška M, Holubová J, Černošková E, Černošek Z, Chromčíková M, Plško A. Nucleation and crystallization of an $\mathrm{As}_{2} \mathrm{Se}_{3}$ undercooled melt. Phys Chem Glasses: Eur J Glass Sci Technol. B 2012;53;289-93.

50. Pilný P. OriTas program - solution for kinetic analysis of thermoanalytical data. http:Ilbyn.wz.cz; https://www.facebook.com/ProjectOriTas

51. Gorbachev VM. Some suggestions for improving the utilization of the function $g(\alpha)$ and $\mathrm{p}(\mathrm{x})$ to identify the mechanism of a thermal transformation. J Therm Anal. 1983;27:1514

52. Wagman DD, Evans WH, Parker VB, Schumm RH. The NBS tables of chemical thermodynamic properties - selected values for inorganic and C-1 and C-2 organic substances in SI units. J Phys Chem Ref Data 1982;11:1 